\title{
Instituições e Políticas Públicas em Territórios da Amazônia: desafios para a capacidade adaptativa e redução de vulnerabilidades
}

\section{Institutions and Public Policies in Amazon Territories: challenges for adaptive capacity and reduction of vulnerabilities}

Jane Simoni - Doutora em Desenvolvimento Sustentável, Universidade de Brasília/UnB 2009, pesquisadora associada do Centro de Desenvolvimento Sustentável, UnB e do Programa Nacional de Pós-Doutorado CAPES e da Rede Clima, sub-rede Mudanças Climáticas e Desenvolvimento Regional. E-mail: jane.simoni@gmail.com

Diego Lindoso - Doutor em Desenvolvimento Sustentável, UnB 2013, consultor IPAM, pesquisador Rede Clima, Sub-rede Mudanças Climáticas e Desenvolvimento Regional. E-mail: diegoplindoso@ gmail.com

Nathan Debortoli - Doutor em Desenvolvimento Sustentável, UnB 2013, pesquisador Rede Clima, Sub-rede Mudanças Climáticas e Desenvolvimento Regional. E-mail: nathandebortoli@gmail.com

Izabel Ibiapina Parente - Mestre em Desenvolvimento Sustentável, UnB 2012, doutoranda em antropologia UnB, pesquisadora Rede Clima, Sub-rede Mudanças Climáticas e Desenvolvimento Regional. E-mail: izabelcip@gmail.com

Guilherme Eidt - Mestre em Direito, Estado e Sociedade, UnB 2008, consultor GIZ. E-mail: guilherme.eidt@gmail.com

\section{Resumo}

O estudo teve como objetivo identificar a percepção de populações locais, formuladores de políticas públicas e tomadores de decisão quanto aos impactos das mudanças climáticas e suas implicações sobre as atividades produtivas locais consolidadas ou em processo de consolidação. Este trabalho apresenta uma análise qualitativa institucional e de políticas públicas presentes no território do Baixo Amazonas - PA e traz proposições de diretrizes para políticas que aumentem a capacidade adaptativa e promovam a redução de vulnerabilidades.

\section{Palavras-chave}

Mudanças climáticas, políticas públicas, capacidade adaptativa, baixo-amazonas, Brasil

\begin{abstract}
This study had as its objective to identify the perception of small-scale farmers/fisherman's, public policies and decision-making actors regarding vulnerability and adaptive capacity to cope with climate change and implications on local productive activities. This work presents qualitative analysis of institutions and public policies that increase adaptive capacity and promote the reduction of vulnerabilities to climate change in the lower-amazon region.
\end{abstract}

\section{Keywords}

Climate change, public policies, adaptive capacity, low-amazon river, Brazil 


\section{INTRODUÇÃO}

A Amazônia será uma das regiões brasileiras que mais intensamente sofrerão com a mudança climática ao longo do século XXI. Os modelos do IPCC projetam aumento das temperaturas 4 a $8^{\circ} \mathrm{C}$ e redução das precipitações com anomalias de -20 a $-60 \%$ no cenário pessimista A2 (MARENGO, 2007). Os impactos serão diferenciados entre setores e serão sentidos em diversas dimensões. O Estado em seus diversos níveis de decisão (municipal, estadual e federal) desempenha um papel chave nos processo adaptativos, atuando em parceria com a sociedade civil e o mercado buscando empreender medidas que fortaleçam capacidades adaptativas e reduzam sensibilidades. No setor agropecuário, os impactos climáticos abrangem diversas dimensões. Por um lado, elevam os custos de produção e, por outro, aumentam os riscos de prejuízos nas atividades rurais, principalmente da produção rural familiar.

A adaptação é um aspecto que está inserido no processo mais amplo de desenvolvimento. Sistemas adaptados são mais estáveis a variações em seu ambiente, de modo que as ações visam promover o desenvolvimento social e econômico. Sistemas muito vulneráveis, em contrapartida, tem medidas de desenvolvimento comprometidas pelos impactos climáticos, os quais reduzem a eficiência de políticas sociais e econômicas, ao mesmo tempo em que competem com recursos e capital político-institucional e financeiro. Estes, em lugar de fomentar o desenvolvimento sustentável, são destinados a lidar com as consequências dos prejuízos climáticos. Ao mesmo tempo, o próprio desenvolvimento é adaptativo, uma vez que a vulnerabilidade faz parte de um contexto multidimensional. Suas determinantes abrangem aspectos sociais, econômicos, ambientais locais e político-institucionais, que interagem no tempo e espaço, tornando o sistema mais susceptível ao evento climático ou reduzindo sua capacidade de prevenir ou reagir aos impactos (SMIT \& SKINNER, 2002).

Assim, frente ao risco climático, o desenvolvimento e a adaptação à mudança climática são agendas que convergem e devem dialogar na prática política. Novas alternativas de desenvolvimento territorial, traduzidas em oportunidades de geração de renda e melhoria da qualidade vida, são essenciais para fortalecer a capacidade adaptativa e a resiliência de sistemas sócioprodutivos. De forma análoga, a redução da vulnerabilidade climática e o fortalecimento da resiliência criam condições para que o desenvolvimento sustentável ocorra. A efetividade de instituições e políticas públicas é chave neste contexto.

Portanto, é importante verificar se as instituições e políticas públicas contribuem para atenuar distúrbios socioeconômicos e impactos decorrentes da

Novos Cadernos NAEA • v. 16 n. 2 • p. 45-66 • dez. 2013 
variabilidade climática (DOVERS, 2009). Neste sentido, não é necessário criar uma nova estrutura política-institucional para enfrentar o problema. No caso da produção rural familiar brasileira, já há um repertório disperso em diferentes ministérios e órgãos da gestão pública que se relacionam com o setor e com os impactos de eventos climáticos extremos. Estes, estão prontos para serem usados na infraestrutura político-institucional de adaptação à mudança climática. $O$ desafio não está na "reinvenção da roda", mas em olhar de forma transversal as políticas existentes em um todo orgânico e articulado, "contaminando" agendas setoriais historicamente isoladas, mas com corresponsabilidade na adaptação da produção rural familiar.

Diante dessa demanda, a pesquisa ora apresentada analisa a estrutura político-institucional relacionada à gestão do uso da terra e produção familiar em dois municípios do Baixo Amazonas (Santarém e Monte Alegre) no Pará, trazendo para o centro da pesquisa a percepção local de atores institucionais e sociais. Este estudo objetivou realizar um diagnóstico institucional e de políticas públicas, (nacionais/estaduais/municipais) ligadas ao uso e ocupação da terra, que favorecem ou não a adaptação dos pequenos produtores rurais. Esses dados, em sua maior parte, foram coletados em pesquisa de campo realizados em junho de 2010, nos municípios elencados e a partir de levantamentos bibliográficos.

\section{AREA DE ESTUDO}

A Mesorregião do Baixo Amazonas é formada por 12 municípios e compreende uma superfície de $340.452 \mathrm{~km}^{2}$, abrigando uma população estimada de 707 mil habitantes (IBGE, 2010). A região ainda possui densa cobertura de vegetação nativa, não obstante haver expressiva ocupação humana concentrada na Microrregião de Santarém (66\% da população) e Microrregião de Óbidos (25\% da população), em comparação com a Microrregião de Almeirim (8\%) (Figura 1).

A região é caracterizada pela pesca artesanal e industrial na região de várzea, e na terra firme, com florestas densas e campos naturais extensos e ricos em nutrientes nos quais predominam a agricultura anual de pequena escala e a pecuária. As regiões de várzeas são caracterizadas por solos férteis e abundância de recursos animais e vegetais. A pesca, como atividade central da várzea, torna-a cerne na economia da região. É importante destacar o fato da situação fundiária em áreas de várzea ser ambígua, pois estas são de propriedade da União mas, estão divididas em posses individuais, coletivas e sujeitas a pressões fundiárias. 
Figura 1 - Localização da mesorregião do baixo amazonas (A) e dos municípios estudados (B). Fonte: elaborado pelos autores a partir da ferramenta 3IGEO, MMA, 2010.

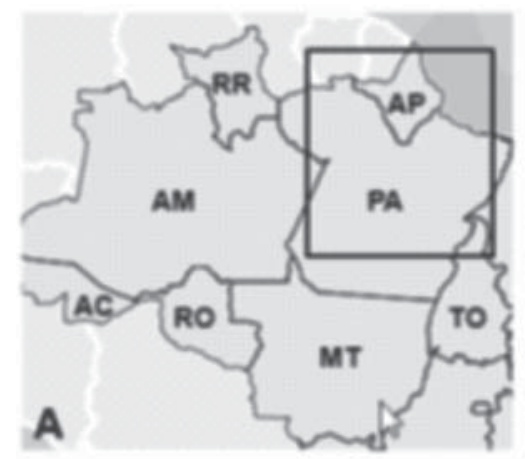

Municipios Visitados

\section{Monte Alegre}

2-Santarèm

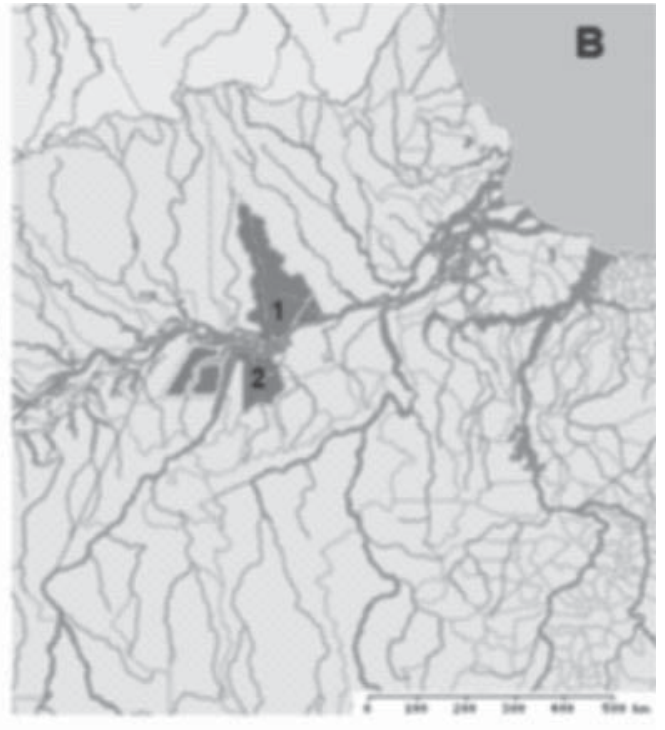

Nos últimos anos o território do Baixo Amazonas vem sendo considerado como uma das principais fronteiras de expansão agrícola. A possibilidade de pavimentação completa da rodovia BR-163 tem motivado o crescimento de cultivos de arroz e soja, bem como o aumento das áreas de pastagem e extração ilegal de madeira. Este fato tem impulsionado a ocorrência de sérios impactos sociais, ambientais e econômicos, tais como: concentração de terra e renda, aumento no fluxo migratório, aumento da violência no campo, poluição de rios, aumento da fragmentação e degradação florestal, dependência da monocultura e a baixa eficiência e aproveitamento econômico de produtos florestais não madeireiros (IPAM, 2010).

\section{METODOLOGIA}

Esta pesquisa teve uma abordagem predominantemente qualitativa, baseada em estudo de caso, em duas localidades que apresentaram problemas com eventos climáticos extremos nos últimos anos (i.e seca, inundações). Foram utilizados como instrumentos de pesquisa entrevistas semiestruturadas e estruturadas, aplicadas a atores chaves (produtores locais; gestores públicos; representantes de organizações locais, municipais, estaduais e federais).

Novos Cadernos NAEA • v. 16 n. $2 \cdot$ p. 45-66 • dez. 2013 
Foram realizadas entrevistas institucionais em sua maioria no município de Santarém, por ser o centro político, econômico e social da região selecionada no estudo. Adicionalmente, entrevistas semiestruturadas com agricultores familiares (ribeirinhos) foram efetuadas no município de Monte Alegre - distante 8 h de barco, à jusante, de Santarém - onde também foram entrevistados representantes de algumas instituições locais para compreender a estrutura de governança municipal em torno da produção familiar. Este município foi escolhido por ser um dos principais do território do Baixo Amazonas, e possuir registros de eventos climáticos extremos com efeito direto na pequena produção agropecuária e na pesca.

Os eixos orientadores das entrevistas foram: políticas existentes no território; capilaridade da instituição; recursos humanos presentes no território; disponibilidade de recursos para execução; cooperação interinstitucional; limitações para desenvolvimento do trabalho; principais resultados alcançados; durabilidade (tempo de existência); rotatividade dos representantes; continuidade das ações; participação nas políticas; e, percepção sobre as mudanças climáticas. Ao total foram realizadas dezoito entrevistas com representantes de organizações governamentais e não governamentais.

\section{RESULTADOS}

O diagnóstico realizado está sintetizado nos quadros a seguir. O quadro institucional do território de estudo incluiu agências governamentais federais, estaduais e municipais e organizações não governamentais atuantes em nível nacional, estadual, regional e local. Essas organizações foram selecionadas por estarem ligadas ao trabalho com o uso e ocupação da terra que favorecem ou não a capacidade adaptativa dos pequenos produtores rurais a eventuais alterações climáticas. O quadro 1 mostra as instituições governamentais e não governamentais entrevistadas em Santarém e Monte Alegre. 
Quadro 1 - Instituições governamentais e não governamentais entrevistadas.

\begin{tabular}{|l|l|}
\hline \multicolumn{1}{|c|}{ Agências Governamentais } & \multicolumn{1}{c|}{ Não governamentais } \\
\hline MMA - ICMBio & $\begin{array}{l}\text { IPAM (Instituto de Pesquisa Ambiental da } \\
\text { Amazônia }\end{array}$ \\
\hline MMA - Sistema Florestal Brasileiro & Programa Saúde e Alegria \\
\hline IDEFLOR & $\begin{array}{l}\text { CEFT-BAM (Centro de Estudo e } \\
\text { Formação do Baixo Amazonas) }\end{array}$ \\
\hline $\begin{array}{l}\text { EMATER Santarém } \\
\text { EMATER Monte Alegre }\end{array}$ & $\begin{array}{l}\text { ITESAM/CNS ( Instituto de Tecnologia } \\
\text { Sustentável para a Amazônia e Conselho } \\
\text { Nacional de Seringueiros) }\end{array}$ \\
\hline $\begin{array}{l}\text { SAGRI - Secretaria de Agricultura } \\
\text { Santarém } \\
\text { Secretaria de Agricultura, Pecuária e } \\
\text { Abastecimento de Monte Alegre }\end{array}$ & $\begin{array}{l}\text { CEAPAC (Centro de Apoio a Projetos } \\
\text { Comunitários) }\end{array}$ \\
\hline $\begin{array}{l}\text { SEMPAF - Secretaria de Agricultura } \\
\text { Familiar }\end{array}$ & Colônia de Pescadores Z-20 Santarém \\
\hline $\begin{array}{l}\text { CIAM (Centro de Informações } \\
\text { Ambientais - Secretaria Planejamento } \\
\text { Santarém) }\end{array}$ & GDA (Grupo de Defesa da Amazônia) \\
\hline $\begin{array}{l}\text { SEMA - Secretaria de Meio Ambiente } \\
\text { Monte Alegre }\end{array}$ & $\begin{array}{l}\text { Sindicato dos Trabalhadores Rurais Monte } \\
\text { Alegre }\end{array}$ \\
\hline
\end{tabular}

Fonte: elaborado pelos autores.

Todas as instituições contempladas neste estudo estão envolvidas com políticas públicas, programas e projetos dirigidos à promoção do desenvolvimento regional/territorial sustentável. Ainda que as agências governamentais estejam diretamente ligadas à implementação das políticas, as entrevistas com atores de organizações não governamentais mostrou que esses também conhecem, sabem operar, possuem massa crítica e visão abrangente referente às políticas públicas existentes, suas potencialidades e fraquezas.

O quadro 2, a seguir, sintetiza as instituições abordadas no trabalho de campo e suas respectivas menções a ações e políticas governamentais percebidas como relevantes ao tema de adaptação a eventos climáticos extremos e/ou mudanças climáticas. 
Quadro 2 - Instituições e menções a políticas e ações percebidas como relevantes para a capacidade adaptativa e a redução de vulnerabilidades.

\begin{tabular}{|c|c|}
\hline Instituições & $\begin{array}{l}\text { Principais políticas/ações mencionadas relacionadas } \\
\text { ao trabalho da instituição ou a percepção de ações } \\
\text { para aumento da capacidade adaptativa e redução de } \\
\text { vulnerabilidades }\end{array}$ \\
\hline MMA - ICMBio & $\begin{array}{l}\text { - PAS - Programa Amazônia Sustentável } \\
\text { - PROMANEJO } \\
\text { - PAC - Luz para Todos } \\
\text { - SISNAMA (Sistema Nacional de Meio Ambiente) } \\
\text { - FNMA (Fundo Nacional do Meio Ambiente) }\end{array}$ \\
\hline $\begin{array}{l}\text { MMA - Sistema } \\
\text { Florestal Brasileiro }\end{array}$ & $\begin{array}{l}\text { - PPCDAM - Plano de Ação para a Prevenção e Controle } \\
\text { do Desmatamento na Amazônia Legal } \\
\text { - PAA - Programa de Aquisição de Alimento - Preço } \\
\text { Mínimo } \\
\text { - PNATER - Programa Nacional de Assistência Técnica } \\
\text { e Extensão Rural } \\
\text {-Terra Legal }\end{array}$ \\
\hline $\begin{array}{l}\text { IDEFLOR - Instituto } \\
\text { de Desenvolvimento } \\
\text { Florestal do Pará }\end{array}$ & $\begin{array}{l}\text { - Gestão florestal } \\
\text { - ZEE - Zoneamento Ecológico Econômico } \\
\text { - Regularização fundiária - Terra Legal }\end{array}$ \\
\hline $\begin{array}{l}\text { EMATER Santarém } \\
\text { EMATER Monte Alegre }\end{array}$ & $\begin{array}{l}\text { - ATER - Assistência Técnica e Extensão Rural } \\
\text { - Terra Legal/ Regularização fundiária } \\
\text { - APLs - Arranjos Produtivos Locais } \\
\text { - CODETER - Conselho de Desenvolvimento Territorial } \\
\text { - PRONAFs - Programa Nacional da Agricultura Familiar } \\
\text { - PAA - Programa de Aquisição de Alimentos } \\
\text { - Projetos Demonstrativos } \\
\text { - Projetos de Assentamento }\end{array}$ \\
\hline $\begin{array}{l}\text { SAGRI - Secretaria de } \\
\text { Agricultura Santarém } \\
\text { Secretaria de Agricultura } \\
\text { Monte Alegre }\end{array}$ & $\begin{array}{l}\text { - Programa Campo Cidadão } \\
\text { - APLs fruticultura, fibras naturais, ovinocaprinocultura, } \\
\text { pesca e aqüicultura, produtos da sociobiodiversidade } \\
\text { - PNTerritórios Rurais - CODETER (Conselho de } \\
\text { Desenvolvimento Territorial) } \\
\text { - PRONAF }\end{array}$ \\
\hline $\begin{array}{l}\text { SEMPAF - Secretaria de } \\
\text { Agricultura Familiar }\end{array}$ & $\begin{array}{l}\text { - Projetos de Assentamento } \\
\text { - Regularização fundiária } \\
\text { - PAA - preço mínimo, merenda escolar }\end{array}$ \\
\hline $\begin{array}{l}\text { CIAM (Centro } \\
\text { de Informações } \\
\text { Ambientais - Secretaria } \\
\text { Planejamento Santarém) }\end{array}$ & $\begin{array}{l}\text { - Plano de ocupação do município } \\
\text { - Planejamento estratégico para o município } \\
\text { - ZEE } \\
\text { - Plano diretor }\end{array}$ \\
\hline
\end{tabular}




\begin{tabular}{|c|c|}
\hline $\begin{array}{l}\text { SEMA - Secretaria de } \\
\text { Meio Ambiente Monte } \\
\text { Alegre }\end{array}$ & $\begin{array}{l}\text { - Fiscalização } \\
\text { - Educação ambiental } \\
\text { - Conselho Municipal de Meio Ambiente } \\
\text { - FNMA } \\
\text { - ICMS Ecológico } \\
\text { - Regularização Fundiária } \\
\text { - ATER } \\
\text { - Projetos de Assentamento }\end{array}$ \\
\hline $\begin{array}{l}\text { IPAM (Instituto de } \\
\text { Pesquisa Ambiental da } \\
\text { Amazônia }\end{array}$ & $\begin{array}{l}\text { - Projeto Várzea (7 municípios e 14mil famílias) } \\
\text { - Projeto Diálogos } \\
\text { - Plano BR-163 } \\
\text { - Testemunhas do Clima } \\
\text { - Apoio a ações de regularização fundiária } \\
\text { - Capacitação e fortalecimento de associações } \\
\text { comunitárias } \\
\text { - Ações em educação ambiental em escolas e em Unidades } \\
\text { de Conservação do Baixo Amazonas } \\
\text { - Mostras e exposições }\end{array}$ \\
\hline $\begin{array}{l}\text { Programa Saúde e } \\
\text { Alegria }\end{array}$ & $\begin{array}{l}\text { - Projetos em saúde e saneamento em comunidades } \\
\text { ribeirinhas } \\
\text { - Projetos de inclusão social } \\
\text { - Projetos em geração de renda (artesanato) } \\
\text { - Ecoturismo de base comunitária } \\
\text { - Capacitação agroecologia e permacultura }\end{array}$ \\
\hline $\begin{array}{l}\text { CEFT-BAM (Centro de } \\
\text { Estudo e Formação do } \\
\text { Baixo Amazonas) }\end{array}$ & $\begin{array}{l}\text { - Educação ambiental } \\
\text { - Programa Amazônia sem Fogo } \\
\text { - Capacitação em associativismo, agroecologia e } \\
\text { diversificação da produção }\end{array}$ \\
\hline $\begin{array}{l}\text { ITESAM/CNS } \\
\text { (Instituto de } \\
\text { Tecnologia Sustentável } \\
\text { para a Amazônia e } \\
\text { Conselho Nacional de } \\
\text { Seringueiros) }\end{array}$ & $\begin{array}{l}\text { - Ações na Resex (Projetos agroextrativistas e de } \\
\text { desenvolvimento sustentável) } \\
\text { - Regularização fundiária (titulação coletiva) } \\
\text { - Ações de educação e capacitação } \\
\text { - Pesquisas em cadeias produtivas da biodiversidade } \\
\text { - Pesquisas em tecnologia de produção } \\
\text { - Plano BR-163 } \\
\text { - FNMA }\end{array}$ \\
\hline $\begin{array}{l}\text { CEAPAC (Centro } \\
\text { de Apoio a Projetos } \\
\text { Comunitários) }\end{array}$ & $\begin{array}{l}\text { - Projeto de agroecologia em PA } \\
\text { - Projeto Roçado Sem Fogo } \\
\text { - PAA - merenda escolar } \\
\text { - Capacitação em associativismo e cooperativismo } \\
\text { - Promoção de seminários e cursos } \\
\text { - Fundação da Casa Família Rural }\end{array}$ \\
\hline
\end{tabular}




\begin{tabular}{|c|c|}
\hline $\begin{array}{l}\text { Colônia de Pescadores } \\
\text { Z-20 Santarém }\end{array}$ & $\begin{array}{l}\text { - Apoio aos pescadores } \\
\text { - Seguro defeso } \\
\text { - Seguridade social (aposentadoria) } \\
\text { - Luz para Todos } \\
\text { - Promoção de cursos e capacitação }\end{array}$ \\
\hline $\begin{array}{l}\text { GDA (Grupo de Defesa } \\
\text { da Amazônia) }\end{array}$ & $\begin{array}{l}\text { - Ações em educação ambiental na Resex e em projetos de } \\
\text { assentamento do Baixo Amazonas }\end{array}$ \\
\hline $\begin{array}{l}\text { Sindicato dos } \\
\text { Trabalhadores Rurais - } \\
\text { Santarém } \\
\text { STR - Monte Alegre }\end{array}$ & $\begin{array}{l}\text { - Regularização Fundiária - Terra Legal } \\
\text { - ATER } \\
\text { - PRONAFs } \\
\text { - Seguridade Social } \\
\text { - Educação } \\
\text { - Saúde } \\
\text { - Pólos de produção agroecológica } \\
\text { - CODETER } \\
\text { - Conselho Municipal de Desenvolvimento Rural } \\
\text { Sustentável } \\
\text { - Plano BR-163 } \\
\text { - Obras PAC - Rodovias, hidrelétricas, logística, } \\
\text { mineração }\end{array}$ \\
\hline
\end{tabular}

\section{DISCUSSÃO}

A análise qualitativa das entrevistas institucionais suscita indagações acerca do papel do Estado brasileiro frente aos desafios locais e regionais característico das condições históricas de ocupação da Amazônia; e, condições sociais, políticas e econômicas em que esta se realiza. Para efetivamente discutir o papel do Estado na Amazônia, é necessário discutir sua legitimidade, formas de intervenção e princípios para uma atuação que atenda os anseios locais e regionais de forma democrática e sustentável (SIMONI, 2009). Esta reflexão deve compreender as instituições, regras seguidas ou em uso, e a maneira como são estabelecidos os mecanismos de monitoramento e apoio a essas regras (OSTROM, 1990; MORAN \& OSTROM, 2009; GREEN et al, 2009). No caso da Amazônia, são vários os desafios a serem enfrentados pelo Estado, e pela sociedade e suas instituições, a começar pela representatividade, participação e envolvimento numa construção coletiva, legítima e criativa das políticas públicas.

Os resultados mostram que as políticas públicas de desenvolvimento territorial rural, em especial, defrontam-se com outras políticas contraditórias, fragmentadas e sem continuidade, que somam-se às barreiras histórico-culturais e ambientais, compondo um cenário de 'esquizofrenia institucional' (SABOURIN, 2008, 2011). Estes, são desafios que precisam ser superados para efetivamente 
incrementar a capacidade adaptativa, e reduzir as vulnerabilidades de agricultores familiares da Amazônia, frente aos possíveis cenários de alterações climáticas.

Uma breve ilustração das políticas contraditórias empreendidas pelo Estado reporta-se ao enfrentamento das características trazidas por um modelo de ocupação desordenado, iniciado há mais de 30 anos, e que perdura até os dias atuais. A necessidade de delimitar áreas para a conservação da biodiversidade e o ordenamento de zonas de ocupação, preconizados pela política do ZEE, esbarram em interesses políticos e econômicos, cujas ações e modelos empreendidos para o uso da terra nem sempre estão em consonância com os objetivos dessa política, e motivam, assim como aponta o Relatório da Comissão Pastoral da Terra (2012, 2013), disputas violentas entre grandes e pequenos produtores rurais.

As contradições persistem e persistirão, enquanto houver interesses antagônicos ponderando pesos iguais e medidas diferenciadas, e principalmente não planejadas para a Amazônia brasileira (SIMONI, 2009). Importante reconhecer que o governo federal (2003-2010), com o auxílio da pressão internacional pela conservação, tem apoiado a iniciativas de pastas como o MMA (Ministério do Meio Ambiente) e MDA (Ministério do Desenvolvimento Agrário), porém essas são pequenas quando relacionadas as cifras de investimento adotadas para a agricultura em grande escala MAPA (Ministério da Agricultura Pecuária e Abastecimento). Este ponto foi destacado por alguns dos entrevistados.

O desperdício de esforços com políticas públicas fragmentadas, com pouca ou nenhuma integraçãoentre elas, caracteriza um ciclo vicioso denotado em entrevistas institucionais realizadas nesta pesquisa. A ausência de planejamento estratégico integrado tem implicações nas ações institucionais das autarquias ligadas às ações de conservação, fiscalização e monitoramento do meio ambiente e da biodiversidade. Um representante do ICMBio em Santarém, por exemplo, relatou ações institucionais pouco integradas para a região do Baixo Amazonas, entre o próprio ICMBio (Instituto Chico Mendes de Conservação da Biodiversidade), IBAMA e SEMA. Se essas instituições pouco interagem entre si, devido a questões políticas e diferenças de infraestrutura, como esperar ações efetivas nesta área? Esta percepção é corroborada pelo representante do Serviço Florestal Brasileiro(SFB), em Santarém, que destaca ser uns dos principais desafios o articulação de ações dentro do próprio MMA, com suas diferentes autarquias, ICMBio, IBAMA e SFB. Isso sem considerar que agências reguladoras de particular importância para o contexto amazônico, como a Agência Nacional de Águas (ANA), estão praticamente ausentes do cenário de implementação de políticas ambientais de conservação na região. 
O imediatismo eleitoreiro, de visão calcada no curto-prazo, também repercute na fragmentação dessas políticas e está relacionado à sobreposições de ações. A Política de Desenvolvimento Regional (PNDR) e a Política de Desenvolvimento Territorial Rural são exemplo disso. A PNDR, com o Plano BR-163 trouxe expectativas em relação às ações dirigidas ao desenvolvimento sustentável da região, mas não implicou em avanços expressivos nessas ações, ou mesmo, alcançaram-se os objetivos propostos no Plano. Mais recente, a Política de Desenvolvimento Territorial e a formação do Conselho de Desenvolvimento Territorial agitam o cenário social no Baixo Amazonas e, novamente, alimentam expectativas que, principalmente, a população rural da região espera sejam correspondidas.

Politicas como o PAC, Luz para Todos e outras ações de desenvolvimento para a região contribuem para essa nova expectativa, porém se observa morosidade nos processos de execução dessas ações. Exemplo disso é o Programa Promanejo, que acabou em 2004, junto com outros pequenos Projetos Demonstrativos financiados pelo Fundo Nacional do Meio Ambiente, na região do Baixo Amazonas, que não foram renovados por falta de recursos financeiros. Esses pequenos projetos estão paralisados há mais de quatro anos, embora sejam de grande importância para comunidades locais, principalmente, porque trazem em seu bojo possibilidades de incremento de renda através da diversificação da produção e dos meios de vida. O que está diretamente ligado à redução da vulnerabilidade. Assim, é necessário um fortalecimento de recursos provenientes do Fundo Nacional de Meio Ambiente(FNMA), e de estruturas como o próprio Sistema Nacional de Meio Ambiente SISNAMA, que apoiam ações deste cunho.

Outro ponto fundamental para a percepção de que as políticas públicas chegam de forma fragmentada na região, é a maneira uniforme com que elas são pensadas, desenhadas, e a forma que devem ser executadas, pretensamente. Reconhece-se a importância deste tipo de abordagem, quando se trabalha em escala nacional. Todavia, realidades locais com circunstâncias tão específicas e peculiares como as da Amazônia brasileira, com aspectos sociais, históricos, políticos, econômicos, culturais e, até mesmo, informacionais e técnicos tão diferentes daqueles observados nas regiões Sul, Sudeste e Nordeste, merecem tratamento próprio. Em muitos aspectos, é difícil operacionalizar e/ou internalizar a visão e proposta inicialmente projetada para uma política pública de abrangência nacional, frente às circunstâncias específicas próprias de realidades sociobiodiversas tão complexas como as da Amazônia (SIMONI, 2009).

Efetivamente, os custos para implementação de ações em comunidades locais da Amazônia envolvem logísticas de transporte, alimentação e infraestrutura 
pouco convencionais e nada facilitadas pelas longas distancias, dificuldades de acesso e reduzida oferta formal de serviços. A complexidade envolvida na efetivação de uma ação faz com que o pouco que se faça crie muita expectativa, e a continuidade das ações seja lenta, e até mesmo frustrante para os gestores e para as comunidades.

A diferença entre escalas de atuação, recepção e incorporação demandadas por algumas políticas públicas as tornam inadequadas e fragmentadas. Pois, não se relacionam com as necessidades e/ou meios locais para efetivação, ou até mesmo com outras políticas locais e regionais. A realidade rural/florestal e ribeirinha demanda ações coordenadas para geração de renda, acesso ao crédito, seguridade social, segurança alimentar, saúde, educação, atenção à questões de gênero e aos jovens, do contrário caem na vala comum da fragmentação.

As políticas contraditórias e fragmentadas estão diretamente relacionadas com a falta de continuidade. Este ponto foi relatado como característico e recorrente pela maioria dos entrevistados. Alguns dos programas necessários na luta contra a pobreza e na oferta de alternativas de diversificação da produção e renda tem infraestrutura debilitada e, ainda encontram pouca sustentação social e política para sua efetivação local, principalmente em contextos que sugerem ou envolvem mudanças no governo em anos eleitorais. No Brasil, são alguns os relatos de pequenos projetos locais ou territoriais que entram em estagnação, ou são anulados quando novos governos tomam posse. Ainda mais se são de partidos políticos opostos. Esta constatação também é evidente na região do Baixo Amazonas.

Barreiras histórico-culturais, como o corporativismo e o clientelismo, completam o cenário institucional, abrindo espaço para comportamentos políticos que corroboram para ações de cunho imediatista, patrimonialista, assistencial, e que fortalecem a dependência socioeconômica e cultural dos agricultores familiares. Tais barreiras geram pressões sociais negativas contra a iniciativa de pequenos agricultores que se auto-desvalorizam, alimentam uma baixa autoestima e reproduzem em suas organizações locais características de ciúme institucional, rivalidade/competição e nepotismo (SABOURIN, 2008, 2009, 2011).

Alguns desses comportamentos foram relatados pelos entrevistados, tanto de instituições governamentais, quanto naquelas entidades ligadas à sociedade civil. Essas barreiras também podem ser constatadas em assimetrias expostas em espaços de negociação, como conselhos, formação de atores e transparência das ações. O rompimento dessas barreiras implica na redefinição, adoção e internalização de princípios da boa governança, feitos a descentralização, o

Novos Cadernos NAEA • v. 16 n. 2 • p. 45-66 • dez. 2013 
empoderamento, a subsidiariedade, a equidade e a transparência na gestão das políticas (BURSZTYN, 2009; FONSECA \& BURSZTYN, 2009).

A sobreposição de políticas públicas e esforços para a participação social faz com que as negociações políticas falem mais alto que os critérios técnicos e sociais. Nessas sobreposições está também a hibridação entre o público, privado, coletivo, individual e comum. As várias faces das políticas públicas contribuem para a sensação paradoxal de ações de engajamento ou desengajamento do Estado, que, por vezes, é tido como ausente e servidor dos interesses do grande capital. Desta maneira, a esquizofrenia se manifesta na característica de presença-ausência do Estado na Amazônia, onde mesmo ausente o Estado é muito presente.

O estudo de caso em Monte Alegre evidencia a falta de diálogo entre os órgãos governamentais. No local onde os pesquisadores realizaram entrevistas com ribeirinhos, verificou-se que há uma sobreposição de unidade de conservação estadual (Parque Estadual Monte Alegre - PEMA) e Projeto de Assentamento Agroextrativista (PAE-PAITUNA). Em entrevista, a SEMA estadual e o INCRA não souberam responder se a área pertencia ao estado do Pará ou à União. Devese ressaltar que a Secretaria de Patrimônio da União (SPU) firmou em 2005 um "Termo de Cooperação Técnica" com o INCRA com objetivo de promover a regularização fundiária em áreas de várzea e implantar Projetos de Assentamento Agroextrativistas (PAE) nestas terras. Assim, com base neste Termo, o INCRA criou o PAE PAITUNA na área de várzea situada ao sul do PEMA (Portaria $n^{\circ}$ 58, de 12 de dezembro de 2006). No entanto, a época, o PEMA já havia sido criado (lei Estadual no 6.412, em 09 de novembro de 2001). Nota-se, portanto, uma total falta de interação entre INCRA e SEMA estadual.

Aspecto essencial à boa execução de ações estratégicas é a infraestrutura de apoio operacional. A política ambiental sem recursos, nas palavras de um servidor do ICMBio em Santarém, é surrealismo: "A sensação é que estamos brincando de fazer política ambiental. A gente não sabe se o que ocorre aqui é um processo de engana povo ou engana Presidente. Não tem uma vez que a gente não vá fiscalizar que não encontremos irregularidade.”

É sabido que a maior parte das Unidades de Conservação (UCs) no Pará, e na Amazônia como um todo, não possui base de apoio operacional para os poucos fiscais que existem. E acontecem operações que demandam dias em atividades de campo. Quando existe uma base, esta possui pouca ou limitada estrutura física e tecnológica, e o efetivo de pessoal lotado nas UCs é pequeno, o que torna a fiscalização e o monitoramento tarefas pouco tangíveis. A efetividade do Código Florestal na região é frágil, e a situação de desflorestamento ilegal domina o cenário. A título de exemplo, convém mencionar o Parque Estadual 
Monte Alegre (PEMA), situado na porção sul do município de Monte Alegre-PA (PARENTE \& BURSZTYN, 2012). Desde meados de 2009, a SEMA possui uma Unidade Regional em Monte Alegre e uma equipe técnica, que atua no local. No entanto, sabe-se que, em agosto de 2011, a unidade de conservação encontravase temporariamente sem gerência. A falta de funcionários qualificados no local certamente dificulta o combate às possíveis irregularidades ambientais.

Outro ponto relatado por gestores da área ambiental diz respeito à sensação geral de impunidade. Muitos dos processos administrativos instaurados em decorrência das fiscalizações realizadas são arquivados por prescrição, sendo que $80 \%$ dos procedimentos de fiscalização não são julgados, nem os bens apreendidos são arrecadados. O conjunto das penalidades prescreve na esfera administrativa e burocrática. A impunidade estimula a prática ilegal e frustra aqueles que estão buscando fazer cumprir a lei.

Os pontos acima citados refletem também a pouca valorização do servidor público na Amazônia. As precárias condições de trabalho e a inexistência de um 'fator Amazônia' na composição salarial embasam a constatação feita por um servidor do SFB em Santarém, de que apesar dos concursos para preenchimento de vagas terem sido realizados, o efetivo pessoal ainda não atende às necessidades do trabalho a ser realizado. Poucos daqueles aprovados nos concursos ficam na região tempo suficiente para iniciar e concluir programas e atividades que exigem gestão e maturação de médio e longo prazo. Muitas remoções e pedidos de transferências acabam refletindo no despreparo dos recursos humanos da região, principalmente, daqueles que buscam apenas cumprir um tempo protocolar de trabalho, até conseguir uma transferência, e não pensam em construir uma vida nas condições oferecidas pela realidade Amazônica.

O servidor do SFB relata grande frustração relacionada à falta de efetivo e de apoio do próprio órgão para ações locais. A centralidade do planejamento das políticas públicas e das ações de controle e fiscalização, vindas de Brasília, implica que as atividades realizadas esqueçam as peculiaridades de uma região onde o setor de serviços praticamente vive na informalidade. Determinações que impedem um mínimo de autonomia regional ou não contam com adequação/ flexibilidade alguma para prestação de contas por parte dos servidores públicos para o abastecimento de combustível e alimentação, como a impossibilidade de uso do cartão de suprimentos ou a exigência de três vias de orçamentos previamente aprovados, mesmo que para realizar atividades em comunidades remotas, forçam as próprias instituições federais a entrarem na informalidade. Servidores fazem estoque de suprimentos, carregam tambores de combustível nos carros e, às vezes, acabam tendo de tirar recursos do próprio bolso para

Novos Cadernos NAEA • v. 16 n. 2 • p. 45-66 • dez. 2013 
trabalhar. A logística de acesso aos lugares onde o SFB atua é complexa, e existe uma percepção de que as ações do Estado estão chegando na região, porém "a cabeça é exponencialmente maior que as pernas e braços, esses são minúsculos".

O nível de descontentamento e frustração dos servidores foi observado e registrado nas entrevistas. Gestores pouco comprometidos, ou "camaleônicos" como definiu um servidor do ICMBio, que atuam conforme o interesse político, financeiro e pessoal. Esta forma de atuação é também devida aos fatores acima explicitados. O representante do ICMBio relata que ações do Instituto estão restritas às apreensões ligadas à madeira ilegal, a fiscalização da fauna e biopirataria estava totalmente parada à época da entrevista. Os servidores trabalham no ritmo das grandes operações especiais, regidos pelo "vício das diárias". Ou seja, só querem participar em operações especiais porque vão receber diárias, que complementam os baixos salários.

Este é um problema gravíssimo na gestão da fiscalização continuada, pois as operações rotineiras são abandonadas. Não existem ações de inteligência para coordenar a fiscalização, principalmente nos pontos de estrangulamento, ou transbordamento das atividades de exploração ilegal de madeira ou biopirataria. Em Santarém, por exemplo, não existia, em 2010, fiscal da SEMA para combater o comércio ilegal de madeira, que saía do porto em containers diretamente para o exterior. As ações estão restritas ao exercício da multa ou das licenças ambientais, e nenhuma prioridade existe para o monitoramento das irregularidades e crimes ambientais. Verificou-se, em Monte Alegre-PA, que o corpo técnico da SEMA municipal também é muito reduzido para empreender fiscalização efetiva. Os acessos por estradas e mesmo através dos rios são precários. Em 2011, trabalhavam na SEMA municipal apenas 10 técnicos para atender uma área municipal de $18.152,508 \mathrm{~km}^{2}$ (área próxima ao território do estado de Sergipe).

Importante notar também que algumas ações de políticas socioambientais na região dependem de outras para serem efetivadas. Um dos exemplos mais claros está na regularização fundiária, a qual é condição primeira para a efetividade de qualquer política pública de gestão florestal, acesso ao crédito e outros benefícios. De alguma forma, uma política pressiona a outra para acontecer. No caso das concessões florestais, segundo o servidor do SFB, o trabalho de concessão está diretamente ligado à regularização fundiária. O trabalho junto ao IDEFLOR (Instituto de Desenvolvimento Florestal/PA), ITERPA (Instituto de Terras do Pará), SEMA e INCRA precisa acontecer para a concessão ser 
efetivada. A política do Terra Legal ${ }^{1}$ talvez seja a mais mencionada por todos os entrevistados, e é percebida como central para o desenvolvimento de ações socioambientais na região. Talvez, seja esta a política pública mais problemática também, por ser carregada de enfrentamento de questões de desordenamento territorial, e vícios políticos enraizados desde há muito na região (LOUREIRO \& PINTO, 2005).

Algumas das dificuldades elencadas pela Secretária Municipal de Agricultura Familiar de Santarém refletem os desafios e contradições já citados, mas merecem ser mais explicitamente colocados. Importa tratar as diferenças sociais, culturais e econômicas da região com flexibilidade e respeito. A questão ambiental ainda não é encarada com a seriedade e a prioridade que deve ter, já que a própria definição de atribuições dos órgãos ambientais não é clara para a sociedade em geral e, inclusive, para alguns de seus servidores. Sem a descentralização das ações, o atendimento do objetivo das políticas públicas frequentemente fica relegado a segundo plano, e ao contrario do esperado, acabam penalizando a execução das ações na agricultura familiar e na pesca. A concentração de renda, terra e poder domina o cenário socioeconômico da região, e continua a fortalecer as barreiras histórico-culturais de desigualdade e injustiça, gerando ações extremamente violentas.

As instituições não governamentais, de maneira geral, e principalmente as com origem local, relatam obstáculos para a execução de seus trabalhos, associados às dificuldades em encontrar pessoas capacitadas para escrever projetos e corpo técnico para os desenvolver. Também foram observados relatos sobre a resistência em fazer avançar a gestão das organizações locais de produtores agrícolas e pescadores com a introdução de princípios do associativismo e cooperativismo. Faltam recursos para investir em infraestrutura e pessoal, e existem limitações em cativar jovens da agricultura familiar para continuar nas atividades rurais/florestais. Foram relatadas frustrações ligadas à morosidade de ações governamentais com comunidades situadas em áreas da RESEX, e em Projetos de Assentamentos (PAs). Os processos de desapropriação são longos, e geram muitos conflitos que resultam em desmatamento e exploração ilegal da madeira, trabalho escravo, ameaça e morte de lideranças.

O trabalho das organizações não governamentais com comunidades que vivem nas áreas das RESEXS e em PAs serve de apoio a centenas de agricultores familiares em busca de regularização fundiária, acesso ao crédito, inclusão social

O Programa Terra Legal foi instaurado no âmbito do MDA, 2009, com o objetivo de regularizar mais de 150 mil posses de terra na Amazonia, tendo os pequenos posseiros como alvos prioritários.

Novos Cadernos NAEA •v. 16 n. $2 \cdot$ p. 45-66 • dez. 2013 
em programas do governo, e capacitação em novos modelos e sistemas de produção. Agroextrativismo, agrofloresta e educação ambiental preventiva, dentre outros temas são considerados trabalhos fundamentais ao mínimo de assistência técnica e suporte às inúmeras comunidades, que há muitos anos vivem à margem das políticas públicas, ou totalmente excluídas de sistemas sociais, políticos e econômicos. Ressalta-se que parte dessas organizações trabalham em parceria com algumas das agências governamentais citadas nesta pesquisa. Existe um bom nível de reconhecimento da importância do trabalho em cooperação interinstitucional para a realização e resultados socioambientais satisfatórios na região.

\section{CONSIDERAÇÕES FINAIS}

A gestão do risco climático não demanda a construção de novas estruturas de governança para lidar com o problema. Já existem políticas públicas e instituições aptas a fortalecer a capacidade adaptativa local e reduzir a vulnerabilidade da produção familiar na região do Baixo Amazonas. Porém, muitas dessas chegam via estruturas institucionalmente fragilizadas do próprio Estado, e transparecem pouca força política e técnica para execução. A percepção de morosidade, fragmentação, falta de continuidade está presente nas falas de agricultores familiares, gestores públicos e representantes de organizações não governamentais e de movimentos sociais. Um dos desafios centrais em um arcabouço político visando a adaptação será fortalecer a estrutura institucional subjacente a processos já em operação.

Importante enfatizar que uma política pública que trate especificamente de adaptações às mudanças climáticas precisa incorporar políticas sociais, econômicas e ambientais. A adequação a fatores climáticos em transformação requer uma integração das ações intersetoriais, que seja capaz de projetar e coordenar respostas nos diferentes níveis de governo, e ao mesmo tempo acompanhar a multiplicidade de acontecimentos peculiares, dispersos entre a escala global e a escala local. A temática também exige a incorporação de visão e planejamento de longo prazo, aspecto ainda desafiador na prática política brasileira. A transversalidade exigida pelas políticas de adaptação coloca o tema das mudanças climáticas dentro de uma agenda de desenvolvimento pautada em novos paradigmas, os quais são sinérgicos com o próprio debate sobre desenvolvimento sustentável.

As políticas mencionadas no quadro 2 influenciam na vulnerabilidade associada aos agricultores familiares. Importante destacar que outras políticas 
nem sequer foram mencionadas como existentes e pertinentes à redução de vulnerabilidades, e aumento da capacidade adaptativa de agricultores familiares da Amazônia.

Prioridade deve ser dada às ações já iniciadas na região, e com algum nível de percepção e expectativa gerada quanto aos seus resultados. Algumas dessas ações estão previstas no Plano BR-163 Sustentável e no Plano de Manejo da Floresta Nacional do Tapajós, e para a RESEX do Tapajós-Arapiuns. Outras foram elaboradas no âmbito dos projetos demonstrativos de arranjos produtivos locais desenvolvidos em áreas de várzea do Baixo Amazonas. Também no âmbito dos conselhos participativos já estabelecidos para o desenvolvimento territorial sustentável e para o desenvolvimento regional, foram estabelecidas ações prioritárias que precisam ser implementadas. O fortalecimento do Programa Terra Legal e a superação dos entraves à sua efetivação são chave para enfrentar talvez, a maior das criticidades para o planejamento e execução de políticas públicas de longo prazo em territórios da Amazônia, a regularização fundiária.

Políticas tipo guarda-chuva, que abarcam outras políticas e ações, como o PPCDAM (BRASIL, 2009), PAS (BRASIL, 2008), Plano BR-163 (BRASIL, 2005, DIALOGOS, 2008) e o próprio Plano Clima, possuem enorme potencial integrador e disseminador de outras políticas importantes para o alcance de resultados, em vista de fortalecer a capacidade adaptativa e redução de vulnerabilidades. Porém, o escopo dessas políticas, por ser abrangente e disperso, fragmenta ações. O desafio posto aos gestores responsáveis pela condução de tais políticas está em encontrar um ponto de equilíbrio entre a abrangência e a especificidade necessária para atender determinado contexto na Amazônia brasileira. As próprias regras para criação de assentamentos pelo INCRA não foram desenhadas e nem contemplam as distintas realidades produtivas de áreas de várzea e terra firme na Amazônia.

As ações do PAC (rodovias, Luz para Todos, hidrelétricas, Plano Amazônia Sustentável) trouxeram a percepção de que as políticas públicas estão voltando a acontecer na região. Pessoas que há muitos anos foram para região por incentivo de políticas de ocupação nos projetos de colonização da década de 1970, e por lá foram 'esquecidas' pelo Estado brasileiro, reportam que há mais de 30 anos não viam alguém que se lhes dirigisse como representante do Estado para falar de perspectivas de melhorias na sua qualidade de vida. Aquelas pessoas que, vivendo sem auxílios governamentais, em meio à floresta ou à beira das rodovias Transamazônica e BR-163, resistiram até hoje às investidas dos grandes fazendeiros e grileiros de terras, continuam a sofrer pressão e correm o risco de serem expulsas de suas terras de forma violenta, com o aumento da 
grilagem e o crescente interesse econômico sobre essas áreas, em face ao avanço do agronegócio para a região. Os índices de violência no campo no Pará são dos mais altos no país (CPT, 2011).

Este ponto, ao que indica algumas entrevistas, é pouco considerado nas consequências trazidas pela implementação de políticas públicas ligadas à regularização fundiária, que ainda não vêm integradas com políticas de valorização do pequeno agricultor e sua produção agrícola, o que favoreceria a permanência na terra. A questão agrária e as políticas agrícolas ainda são temas que precisam encontrar gestão adequada para superar o desafio posto pelo avanço do agronegócio nas áreas de fronteira do arco do desmatamento na região Amazônica, frente às potencialidades do desenvolvimento econômico sustentável das atividades agroextrativistas.

Os planos e programas acima mencionados (PPCDAM, PAS, Plano BR-163), entre outros, são exemplos de iniciativas governamentais que ilustram boa compreensão dos impasses colocados para a região e projetam ações bem orientadas para o enfrentamento das complexas questões socioeconômicas e ambientais presentes no território amazônico. A realidade da implementação dessas políticas ainda está longe de atender às demandas de fortalecimento e melhor da qualidade de vida na agricultura familiar, em sintonia com os propósitos de desenvolvimento rural sustentável para a região. A incorporação de aspectos da boa governança no planejamento e execução das políticas públicas na Amazônia é essencial para direcionar e coordenar ações capazes de prevenir e minimizar possíveis impactos e riscos decorrentes das mudanças climáticas nesses territórios.

\section{AGRADECIMENTOS}

Gostaríamos de agradecer a equipe da EMATER de Santarém e Monte Alegre. Em Santarém, Paulo Sergio forneceu o apoio necessário as entrevistas institucionais. Em Monte Alegre, Pepe e Juarez Pantoja, forneceram apoio fundamental para realização das entrevistas com agricultores familiares. Este trabalho foi realizado com o apoio da Secretaria de Assuntos Estratégicos da Presidência da República, via Programa das Nações Unidas para o Desenvolvimento - PROJETO BRA/06/032. Agradecemos também ao CNPQ e à CAPES/PNPD. 


\section{REFERÊNCIAS BIBLIOGRÁFICAS:}

ADGER, W. N., et al. Are there social limits to adaptation to climate change?Climatic Change, 93, nº. 3-4. 2009.

AZEVEDO, A. et al. Mudanças climáticas, vulnerabilidade e capacidade adaptativa de territórios da Amazônia: Mato Grosso.Estudo Técnico. PNUD/ SAE. 2010.

BECKER, B. Síntese do processo de ocupação da Amazônia - lições do passado e desafios do presente.Causa e Dinâmica do Desmatamento na Amazônia. MMA. 5- 28p. Brasília. 2001.

BECKER, B. A Amazônia e a Política Ambiental Brasileira. In: Santos, M., et al. Território, territórios: ensaios sobre o ordenamento territorial. 22-40p. DP\&A. Rio de Janeiro. 2007.

BRASIL. Plano de Desenvolvimento Regional Sustentável para a Área de Influência da BR-163 (Rodovia Cuiabá-Santarém). In: Casa Civil / Presidência da República. Brasília. 2005.

BRASIL. Plano de Ação para a Prevenção e Controle do Desmatamento na Amazônia Legal (PPCDAM). In: Casa Civil/ Presidência da República. Brasília. 2009.

BRASIL. Plano Amazônia Sustentável: diretrizes para o desenvolvimento sustentável da Amazônia Brasileira. In: Presidência da República. MMA. Brasília. 2008.

BURSZTYN, M. Think locally, act globally: new challenges to environmental governance. In: Harvard University. WorkingPapers, Online, v.33, p.1-45. 2009.

CPT. Conflitos no Campo - Brasil 2012. Antonio Canuto, Cássia Regina da Silva Luz ,Flávio Lazzarin (Organizadores). Goiânia. 188p. Comissão Pastoral da Terra Nacional - Brasil, 2013.

CPT. Conflitos no Campo Brasil 2011. Antônio Canuto, Cássia Regina da Silva Luz, IsoleteWichinieski(Organizadores). Goiânia. 182p. Comissão Pastoral da Terra Nacional- Brasil, 2012.

DIALOGOS, Projeto. Desenvolvimento Territorial: Diretrizes para a Região da BR-163. In: UnB/CDSWWF, IPAM, ICV, CIRAD. 2008.

DI FALCO S; VERONESI M, \& YESUF M. Does adaptationtoclimatechangeprovidefoodsecurity? A micro-perspective fromEthiopia.American JournalofAgriculturalEconomics 93, n $\mathrm{n}^{\circ} 3$ p.825842. 2011. 
DOVERS, S. Normalizing adaptation. Global Environmental Change. 19. n. 1. 4-6. 2009.

FONSECA, I. F.\&BURSZTYN, M. A banalização da sustentabilidade: reflexões sobre governança ambiental em escala local. Sociedade e Estado (UnB. Impresso). , v.24, p.17 - 46, 2009.

GREEN, G.M.; SCHWEIK, C.M. \& RANDOLPH, J.C. Integrando disciplinas no espaço e no tempo: conceitos e abordagens úteis para estudos de mudanças de cobertura da terra. In: MORAN, E. e OSTROM, E. (orgs). Ecossistemas Florestais: Interação Homem-Ambiente. 87-108p.Editora Senac, Edusp. São Paulo. 2009.

HOWDEN, S. M. et al. Adaptingagriculturetoclimatechange. ProceedingsoftheNationalAcademyofSciencesofthe United Statesof America 104, no 50 p.19691-19696. doi:10.1073/pnas.0701890104. 2007

IBGE. http://www.ibge.gov.br/estadosat/perfil.php?sigla=pa, acessado em 07/07/2010.

IBNOUF, F. O. Challengesandpossibilities for achievinghouseholdfoodsecurity in the Western Sudanregion: the role offemalefarmers. Food Security 3, $\mathrm{n}^{\circ} 2$ p.215-231. 2011.

IPAM. http://www.ipam.org.br/o-ipam/ acesso em 20/08/2010.

LINDOSO, D. et al.. Vulnerabilidade socioeconômica da agricultura familiar brasileira às mudanças climáticas: o desafio da avaliação de realidades complexas.

Boletim Regional, Urbano e Ambiental -IPEA. Brasília. 2010.

LOUREIRO, V. R. \& PINTO, J.N. A Questão Fundiária da Amazônia.Estudos Avançados. 19. no.54. 77-98. 2005.

MARENGO, J. A. Mudanças Climáticas Globais e Efeitos sobre a Biodiversidade - Caracterização do Clima no Século XX e Cenários Climáticos no Brasil e na América do sul para o Século XXI derivados dos modelos Globais de Clima IPCC. CPTEC/INPE. São Paulo, p.185. 2007

MELlo, N. A. Políticas Territoriais na Amazônia.Anna Blume. São Paulo. 2006.

MORAN, E. e OSTROM, E. Ecossistemas Florestais: Interação HomemAmbiente. Editora Senac, Edusp. São Paulo. 2009.

O'BRIEN, K. et al. Mapping vulnerability to multiple stressors: climate change and globalization in India.Global Environmental Change, n. 14, p. 303-313. 2004. 
OSTROM, E. GoverningtheCommons: theEvolutionofInstitutions for CollectiveAction. Cambridge University Press. New York. 1990.

PARENTE, I. \& BURSZTYN, M. Conflitos em Unidades de Conservação na Amazônia: o caso do Parque Estadual Monte Alegre - Pará. Novos Cadernos NAEA. V15, n. 2, p. 21-44. Dez. 2012

ROCHA, J. et al. Mudanças climáticas, vulnerabilidade e capacidade adaptativa de territórios da Amazônia: Acre. Estudo Técnico. PNUD/SAE.2010.

SABOURIN, E. Renovação dos instrumentos de desenvolvimento e extensão rural.Cadernos do CEAM (UnB). v. 29. p. 79-102. 2007.

SABOURIN, E. P. Reflexão sobre métodos e políticas públicas: que renovação dos instrumentos de desenvolvimento e extensão rural.Sociedade e Desenvolvimento Rural. v. 1. p. 4. 2008.

SABOURIN, E. P. Camponeses do Brasil: entre a troca mercantil e a reciprocidade.Garamond. Rio de Janeiro. 2009.

SABOURIN, E. P. Paternalismo e clientelismo como efeitos da conjunção entre opressão paternalista e exploração capitalista.Estudos Sociedade e Agricultura. v. 19 . p. 5-29. 2011.

SAYAGO, D.; TOURRAND, J. e BURSZTYN, M. Amazônia: Cenas e Cenários. Brasília. Editora Universidade de Brasília. 2004. 382p.

SAYAGO, D. \& BURSZTYN, M. Amazônia: Um mosaico de projetos. In: NASCIMENTO, E. e DRUMMOND, J. A. Amazônia: Dinamismoeconômico e conservação ambiental. p.165-190. Rio de Janeiro. Garamond. 2003.

SIMONI, J. et al. Mudanças climáticas, vulnerabilidade e capacidade adaptativa de territórios da Amazônia: Pará.Estudo Técnico.PNUD/SAE. 2010.

SIMONI, J. A multidimensionalidade da valorização de produtos locais: implicações para políticas públicas, mercado, território e sustentabilidade na Amazônia.Tese de doutorado. 391. Desenvolvimento Sustentável. Universidade de Brasília. 2009.

SMIT, B. \& SKINNER, M. Adaptation options in agriculture to climate change: a typology. In: Mitigation and Adaptation Strategies for Global Change. 7, no 1 p.85-114. 2002 